\title{
Ascorbic acid attenuates ethanol induced apoptotic and oxidative response by blocking the Bax, Bcl2 and Caspase signaling pathways
}

\author{
Nathiya Shanmugam ${ }^{1 *}$, Rajaram Siddharaman², Manivannan Ekambaram², \\ Ramya Rajendran ${ }^{2}$, Yasothai Ramasamy ${ }^{1}$, Ashwinidevi Balasubramanian ${ }^{1}$
}

\begin{abstract}
${ }^{1}$ Department of Pharmacology, Sri. Ramakrishna Dental College and Hospital, Coimbatore, Tamil Nadu, India ${ }^{2}$ Department of Pharmacology, Vinayaka Mission Kirupanantha Variyar Medical College and Hospital, Vinayaka Mission Research Foundation, Salem, Tamil Nadu, India
\end{abstract}

Received: 14 December 2021

Accepted: 05 January 2022

\section{*Correspondence:}

Dr. Nathiya Shanmugam,

Email: nathissh@gmail.com

Copyright: (C) the author(s), publisher and licensee Medip Academy. This is an open-access article distributed under the terms of the Creative Commons Attribution Non-Commercial License, which permits unrestricted non-commercial use, distribution, and reproduction in any medium, provided the original work is properly cited.

\begin{abstract}
Background: Research evidence has demonstrated that oxidative stress plays important etiological role in pathogenesis of alcoholic liver disease. The agents having antioxidant property plays a promising therapeutic intervention in ALD. In our present study we investigate the effect of ascorbic acid on ethanol induced liver injury and molecular mechanism of ethanol induced apoptosis.

Methods: Wistar albino rats were randomly divided into 4 groups with 6 animals in each group control, ethanol treatment $40 \%(2 \mathrm{ml} / 100 \mathrm{gm})$, ethanol+ascorbic acid $100 \mathrm{mg} / \mathrm{kg}$ b.w. intra-gastric gavage, ethanol+silymarin $100 \mathrm{mg} / \mathrm{kg}$ b.w. intra-gastric gavage for 21 days. Statistical analysis was carried out using one-way ANOVA followed by Tukey multiple comparision test.

Results: Ethanol induced hepatotoxicity is evidenced by increased level of liver marker enzymes (AST, ALT, ALP and $\mathrm{LDH}$ ) and lipid peroxidation whereas the level of antioxidants (SOD, CAT, GSH, VIT C and E) was significantly decreased. Our results are further supported by histopathological examination which shows drastic changes in liver architecture. Hepatic Bax, Bcl-2, Caspase 3 and Caspase 9 proteins expressions were altered. On contrary treatment with ascorbic acid ameliorated the changes induced by ethanol and improved liver architecture.
\end{abstract}

Conclusions: Ascorbic acid as an antioxidant protect the liver from ethanol induced oxidative damage and apoptosis.

Keywords: Apoptosis, Ascorbic acid, Antioxidant, Caspase, Ethanol, Oxidative stress

\section{INTRODUCTION}

Excessive alcohol consumption is the serious problem in our society. Chronic use of alcohol leads to cirrhosis, intestinal haemorrhage and also it modulates the immune system both directly as well as through associated complications like malnutrition and neurological abnormalities. Ethanol can trigger the apoptosis in macrophages and neutrophils and modulate the immune function directly. ${ }^{1}$ Nearly about $80-90 \%$ of alcohol is oxidized to acetaldehyde in the liver. This process is catalysed by different enzymes like alcohol dehydrogenase (ADH), microsomal ethanol metabolizing system (MEOS) and acetaldehyde dehydrogenase (ALDH). Acetaldehyde is the more toxic metabolite of ethanol which leads to a number of metabolic disorders in the liver.

Acute ethanol administration produces lipid peroxidation in the liver, which is an indicator of oxidative stress. 
Increased oxidative stress occurs directly due to ethanol and its toxic metabolite. The important factor that plays a central role in the aetiopathology of alcohol-induced liver disease and which has been the focus of much research is the excessive generation of ROS. Moreover, it was reported ethanol could induce organ damage by activating apoptotic death which were manifested by an increase in the expression of Caspase-3, Caspase-9, Bax protein as well as by a decrease in B-cell lymphoma-2 (Bcl-2) expression. ${ }^{2,3}$ Thus, numerous interventions have been put forward to counteract the vulnerability of the liver to oxidative challenges during alcohol consumption by reinforcing the endogenous antioxidant defence system. ${ }^{4}$ Vitamin $\mathrm{C}$ (ascorbic acid) is an essential watersoluble micronutrient in humans and it is obtained through the diet, primarily from citrus (orange), kiwi fruit, papaya, berries and green leafy vegetables. While kidney and liver are good animal-derived sources of Ascorbic acid. ${ }^{5,6}$ Vitamin $\mathrm{C}$ shows protective effect against paracetomol, carbon tetra chloride, malathion and radiation induced hepatotoxicity. Hepatoprotective property of Vitamin $\mathrm{C}$ is attributed to its antioxidant property. Vitamin $\mathrm{C}$ exerts its antioxidant action by inhibiting lipid peroxidation and oxidative cell damage either directly or indirectly by regenerating vitamin $\mathrm{E}^{7}$ Hence the present study was designed to evaluate the protective effect of ascorbic acid against ethanol induced hepatotoxicity and apoptosis.

\section{METHODS}

\section{Reagents and solvents}

All the chemicals and solvents used were of analytical grade. The standard drug silymarin and Ascorbic acid were purchased from Sigma- Aldrich, USA. Standard kits for AST, ALT, and ALP etc. were obtained from Transasia Bio-Medicals, Bangalore. All other chemicals and solvents used in the study were of analytical grade. Orogastric cannula was used for drug administration.

\section{Animals}

Adult male Wistar rats (150-200g) were supplied by central animal house VMKVMC, Salem and used for experiments after 1 week of acclimatization. The animals were housed at normal atmospheric temperature and humidity with constant $12 \mathrm{~h}$ light and $12 \mathrm{~h}$ dark schedule. Animals were fed on standardized diet for rodents and water ad libitum.

\section{Treatment regimens}

Ethanol (EtOH), silymarin (SLY) and ascorbic acid (AA) was dissolved in sterile distilled water. The dose of ethanol, silymarin and ascorbic acid used in this study was selected on the basis of the previous study..$^{8-10}$

\section{Study design}

The study was done in VMKV medical college and hospital, Salem. The animals were randomly divided into four groups of 6 animals each such that the weight difference within and between groups does not exceed $\pm 20 \%$ of the average weight. The experiment was conducted over a period of 21 days. Group 1: control rats received distilled water intra-gastric gavage (i.g.) for a period of 21 days. Group 2: toxic control rats received ethanol $40 \%(2 \mathrm{ml} / 100 \mathrm{gm})$ intra-gastric gavage for a period of 21 days. Group 3: rats received ascorbic acid $100 \mathrm{mg} / \mathrm{kg}$ b.w. intra-gastric gavage $1 \mathrm{~h}$ before oral administration of ethanol $40 \%(2 \mathrm{ml} / 100 \mathrm{gm})$ for a period of 21 days. Group 4: Standard group rats received silymarin $100 \mathrm{mg} / \mathrm{kg}$ b.w. intra-gastric gavage $1 \mathrm{~h}$ before oral administration of ethanol $40 \%(2 \mathrm{ml} / 100 \mathrm{gm})$ for a period of 21 days.

At the end of the experimental period the animals were fasted over night and anaesthetized with ether. Then the blood was collected by retro orbital vein puncture and serum was separated to determine the biochemical parameters. After that the animals were sacrificed by cervical dislocation. The liver was immediately dissected out; weighed and washed using chilled saline solution. Tissues were minced and homogenized, in ice-cold buffer (pH 7.4) using a glass homogenizer. The homogenate was used for the determination of biochemical parameter. The remaining liver was fixed in $10 \%$ formalin solution for histological analysis.

\section{Biochemical estimations}

Estimation of liver marker enzymes: the liver marker enzymes Bilirubin, AST, ALT, ALP, and LDH were assayed by using commercially available Standard kit (Transasia bio-medicals, Bangalore). Estimation of oxidative stress markers: the level of tissue thiobarbituric acid reactive substances (TBARS/LPO) was measured using the method of Ohkawa et al. ${ }^{11}$ Estimation of Enzymatic and non-enzymatic antioxidants: superoxide dismutase (SOD) was assayed by the method of Kakkar et al. ${ }^{12}$ The activity of catalase (CAT) was determined by the method of Sinha. ${ }^{13}$ Reduced glutathione (GSH) activity was assayed by the method of Rotruck et al. ${ }^{14}$ Ascorbic acid (vitamin C) and tocopherol (vitamin E) content were estimated by the methods of Omaye et al and Desai et al. ${ }^{15,16}$ Estimation of total protein; the total protein content was determined by the method of Lowry et al. ${ }^{17}$

\section{Histological examination}

The rat liver was quickly removed after sacrifice of rats and was fixed with $10 \%$ formalin solution. Histological sections were prepared, stained with haematoxylin and eosin and then examined under microscope. 


\section{Western blotting analysis}

Tissue sample of liver were subjected to lyse in the sample buffer and the protein concentration of lysates was determined. The Bradford protein estimation kit was used to determine the concentrate of the protein in the lysate. From the each sample equal amount $(40 \mu \mathrm{g})$ of liver tissue proteins are subjected to $12 \%$ SDS-PAGE gels. Then it is transferred onto PVDF membranes. Then membranes were then probed with the respective primary antibodies (rabbit polyclonal antibody) against $\mathrm{Bax}, \mathrm{Bcl}$ 2, Caspase- 3 and Caspase 9 overnight at $4^{\circ} \mathrm{C}$. After that wash the each membrane and then incubated with horseradish peroxidase (HRP)-labelled anti-rabbit secondary antibodies for 1hour at room temperature. The protein bands were visualized by enhanced chemiluminescent HRP substrate (ECL) kit (Amersham Bioscience) according to the manufacturer's instructions. The expression levels were quantified using the image $\mathrm{J}$ analysis (version 1.43, NIH, USA) for Windows. Blots were reported with $\beta$-actin antibody as a loading control.

\section{Statistical analysis}

Results were expressed as mean \pm SD $(n=6)$. Statistical analysis was carried out using one-way ANOVA followed by Tukey HSD Post multiple range test, $\mathrm{p}<0.05$ was considered statistically significant.

\section{RESULTS}

\section{Effect of ascorbic acid on total protein and bilirubin}

The effects of ascorbic acid on the serum level of Bilirubin and total protein was shown in (Figure 1).
Ethanol administration significantly elevated $(\mathrm{p}<0.001)$ the level of serum Bilirubin. On contrary ethanol significantly $(\mathrm{p}<0.001)$ decreased the level of total proteins when compared to the control group. Treatment with ascorbic acid significantly $(p<0.001)$ reduced the level of serum bilirubin and significantly $(\mathrm{p}<0.001)$ increased the level of total protein when compared to ethanol group. Similarly Standard drug silymarin significantly $(p<0.001)$ reduced the level of serum bilirubin and significantly $(\mathrm{p}<0.001)$ increased the level of total protein when compared to ethanol group.

\section{Effect of ascorbic acid on serum marker enzymes}

The effect of ascorbic acid on serum marker enzymes AST, ALT, ALP and LDH were shown in the (Table 1). Ethanol administration significantly $(\mathrm{p}<0.001)$ elevated the serum marker enzymes (AST, ALT, ALP and LDH). Alternatively, Cotreatment with ascorbic acid significantly $(\mathrm{p}<0.001)$ decreased the level of serum marker enzymes when compared to ethanol treated group. Standard drug Silymarin also significantly $(\mathrm{p}<0.001)$ reversed the biochemical changes induced by alcohol.

\section{Effect of ascorbic acid on lipid peroxidation in the liver of ethanol intoxicated rats}

In Alcohol administered group the level of Lipid per oxidation $(\mathrm{p}<0.001)$ was significantly increased when compared to the control group. In group supplemented with ascorbic acid the level of lipid peroxidation was significantly $(\mathrm{p}<0.001)$ decreased when compared to the ethanol treated group (Figure 2A).

Table 1: Effect of ascorbic acid on serum marker enzymes.

\begin{tabular}{|lllll|}
\hline Serum & $\begin{array}{l}\text { Control } \\
\text { mean } \pm \text { SD }\end{array}$ & $\begin{array}{l}\text { EtOH } \\
\text { mean } \pm \text { SD }\end{array}$ & $\begin{array}{l}\text { EtOH+AA } \\
\text { mean } \pm \text { SD }\end{array}$ & $\begin{array}{l}\text { ETOH+SLY } \\
\text { mean } \pm \text { SD }\end{array}$ \\
\hline AST (IU/I) & $17.50 \pm 1.10$ & $64.31 \pm 3.72^{* * *}$ & $30.00 \pm 2.83^{\mathrm{c}}$ & $26.34 \pm 0.87^{\mathrm{c}}$ \\
\hline ALT (IU/I) & $45.31 \pm 2.58$ & $105.81 \pm 5.27^{* * *}$ & $76.41 \pm 2.80^{\mathrm{c}}$ & $60.72 \pm 1.64^{\mathrm{c}}$ \\
\hline ALP (IU/l) & $188.50 \pm 5.36$ & $284.19 \pm 4.56^{* * *}$ & $218.93 \pm 1.91^{\mathrm{c}}$ & $191.15 \pm 1.66^{\mathrm{c}}$ \\
\hline LDH (IU/I) & $3.08 \pm 0.17$ & $10.26 \pm 1.13^{* * *}$ & $5.05 \pm 0.71^{\mathrm{c}}$ & $3.97 \pm 0.21^{\mathrm{c}}$ \\
\hline
\end{tabular}

${ }^{* * *} \mathrm{p}<0.001$ compared to control group, ${ }^{\mathrm{c}} \mathrm{p}<0.001$ compared to ethanol group.

Table 2: Effect of ascorbic acid on vitamin $C$ and vitamin $E$ in the liver of ethanol intoxicated rats.

\begin{tabular}{|lllll|}
\hline Liver serum & $\begin{array}{l}\text { Control } \\
\text { mean } \pm \text { SD }\end{array}$ & $\begin{array}{l}\text { EtOH } \\
\text { mean } \pm \text { SD }\end{array}$ & $\begin{array}{l}\text { EtOH+AA } \\
\text { mean } \pm \text { SD }\end{array}$ & $\begin{array}{l}\text { ETOH+SLY } \\
\text { mean } \pm \text { SD }\end{array}$ \\
\hline $\begin{array}{l}\text { Vitamin C } \\
\text { mg/g of wet tissue }\end{array}$ & $2.31 \pm 0.18$ & $1.02 \pm 0.10^{* * *}$ & $2.16 \pm 0.08^{\mathrm{c}}$ & $2.32 \pm 0.14^{\mathrm{c}}$ \\
\hline $\begin{array}{l}\text { Vitamin E } \\
\text { mg/g of wet tissue }\end{array}$ & $8.18 \pm 0.17$ & $3.24 \pm 0.04^{* * *}$ & $6.04 \pm 0.15^{\mathrm{c}}$ & $7.82 \pm 0.53^{\mathrm{c}}$ \\
\hline
\end{tabular}

${ }^{* * * *} \mathrm{p}<0.001$ compared to control group, ${ }^{c} \mathrm{p}<0.001$ compared to ethanol group. 


\section{Effect of ascorbic acid on antioxidant enzymes in the liver of ethanol intoxicated rats}

Ethanol treatment had significantly brought down the level antioxidant enzyme SOD, CAT and GSH (Figure 2) were significantly decreased $(\mathrm{p}<0.001)$ in ethanol treated groups when compared to the normal control. The group Supplemented with ascorbic acid level SOD $(\mathrm{p}<0.01)$, CAT $(p<0.001)$, GSH $(p<0.001)$. Similarly, ethanol intoxication significantly decreased the level of VIT $C$ $(\mathrm{p}<0.001)$ and $\mathrm{E}(\mathrm{p}<0.001)$ whereas ascorbic acid coadministration reinstituted the diminished level of VIT C $(\mathrm{p}<0.001)$ and $\mathrm{E}(\mathrm{p}<0.001)$ when compared to the alcohol treated group (Table 2).

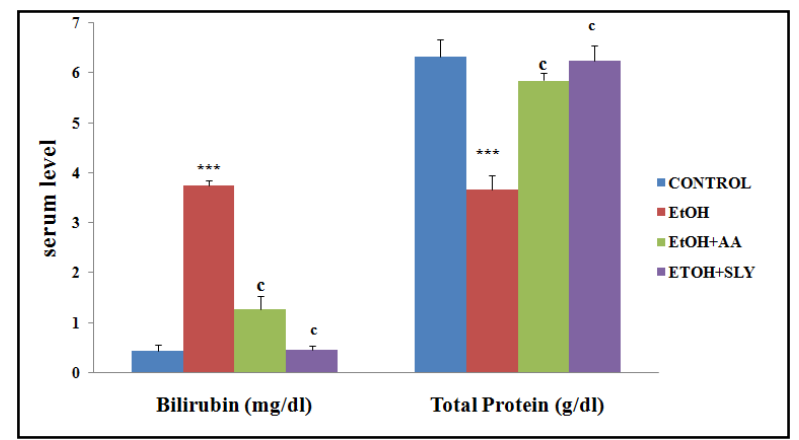

Figure 1: Effect of ascorbic acid on bilirubin and total protein $\left({ }^{* * * *} \mathbf{p}<0.001\right.$ compared to control group, ${ }^{c} \mathbf{p}<0.001$ compared to ethanol group).

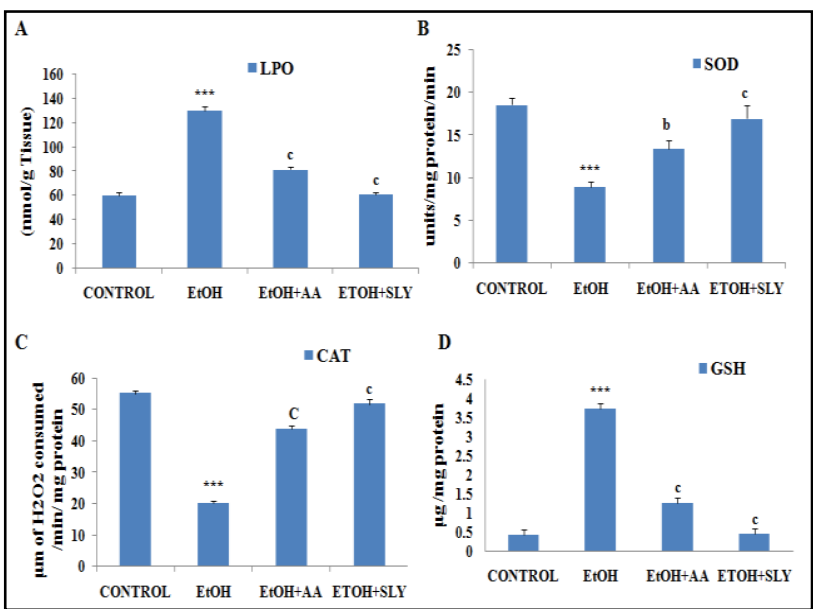

Figure 2: Effect of ascorbic acid on lipid peroxidation and antioxidant enzymes in liver, A) lipid peroxidation, B) superoxide dismutase, C) catalase, D) glutathione.

\section{Effect of ascorbic acid on histopathological changes in liver}

The histopathological examination of liver was represented in the (Figure 3A-D). The liver of control rats shows the normal liver architecture. The liver of ethanol intoxicated rats shows the drastic changes in liver architecture with central vein and sinusoidal congestion and disturbed lobular architecture. In contrast rats treated with ascorbic acid shows mild sinusoidal congestion with near normal architecture. Treatment with Silymarin shows normal liver architecture.

\section{Effect of ascorbic acid on apoptotic markers}

Western blotting: the protein expression of BAX \& Bcl-2 was shown in the (Figure 4A). Ethanol increases the protein expression of pro apoptotic Bax and decrease the level of antiapoptotic Bcl2. Ascorbic acid administration significantly down regulated the expression of Bax and unregulated the expression of $\mathrm{Bcl}-2$. The protein expression of Caspase 3 and Caspase 9 were shown in the (Figure 4B). The protein expression of Caspase 3 and Caspase 9 were elevated in ethanol treated group whereas treatment with ascorbic acid reduced the expression of Caspase 3 and Caspase 9.
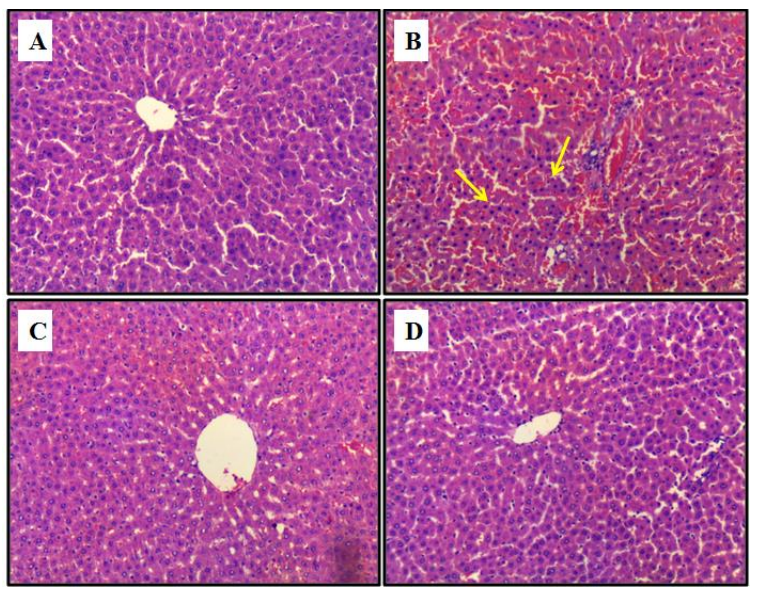

Figure 3: Liver histopathology (400X), A) control rat liver, B) rats treated with ethanol shows central vein and sinusoidal congestion and disturbed lobular architecture, C) rats treated with ascorbic acid shows mild congestion with near normal architecture, D) treatment with Silymarin shows normal liver architecture.

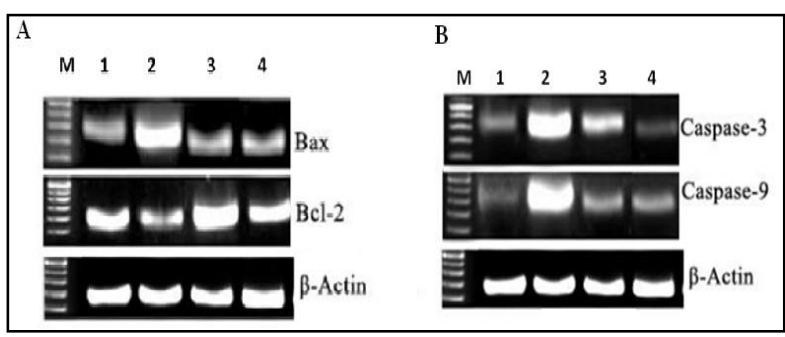

Figure 3: A) Protein expression of Bax and Bcl-2, B) protein expression of Caspase 3 and Caspase 9.

\section{DISCUSSION}

Alcohol is one of the major causes of end-stage liver disease across the world. The majority of ethanol is metabolized in the liver and individuals who abuse 
alcohol by routinely drinking 50-60 g (about 4 to 5 drinks) of ethanol per day are at risk of developing alcoholic liver disease. Formation of reactive oxygen species (ROS), oxidative stress and hepatic cell necrosis have been implicated in alcoholic liver disease. ${ }^{18}$ Research evidence suggested that ethanol induced liver damage is mediated through generation of ROS during acetaldehyde oxidation. ${ }^{19}$ The ethanol or its metabolites stress the peroxidative balance of the liver cell towards autoxidation either by acting as a pro-oxidant or by lowering the cellular antioxidant level. Tuma et al. have shown that rat liver produced large amounts of MDA and acetaldehyde after oral administration of ethanol. Similarly in the present study, ethanol administration significantly increase the level of TBARS, this might be due to acetaldehyde induced peroxidative damage to the membrane lipids. ${ }^{20}$ This peroxidative damage will altered the permeability and functional integrity of cell membrane which result in the leakage of cellular content into the circulation. This might be the reason for increased levels of serum bilirubin, AST, ALT and ALP in ethanol intoxicated rats. Our results are similar to that of the results of Zima et al. ${ }^{19}$ The implication of oxidative stress in ethanol toxicity would imply that either ethanol is converted to a free radical intermediate during metabolism or ethanol or its metabolites react with some nucleophile in an antioxidant molecule and decreasing the antioxidant potential. ${ }^{21}$ This might be the possible reason for significant increase level of TBARS and significant decrease in the level of SOD, CAT, GSH, vitamin $\mathrm{C}$ and $\mathrm{E}$ which was observed in our present study. SOD take part in maintain the GSH homeostasis in tissues. GSH plays a central role in co-ordinating the body antioxidant defense process and also control the glutathione related enzymes. ${ }^{22}$ Depletion of GSH in our studies clearly indicates that the hepatocyte was more susceptible to oxidative stress. The non-enzymatic antioxidant like vitamin $\mathrm{C}$, vitamin $\mathrm{E}$ and reduced glutathione are closely interlinked with each other and play an excellent role in protecting the cell from lipid peroxidation. ${ }^{23}$ In our present study the decline in the activities of enzymatic and non-enzymatic antioxidant levels on ethanol exposure may be due to the involvement of these enzymes in the detoxification of ROS and possible repair mechanism in liver. Concurrent treatment with ascorbic acid significantly lowers the level of lipid peroxidation and restores the activities of SOD, CAT, GSH, vitamin $\mathrm{C}$ and vitamin $\mathrm{E}$ in liver in our present study. Earlier studies have shown ascorbic acid to be a potent antioxidant which mediates its antioxidant effect by scavenging free reactive oxygen species (ROS). ${ }^{24}$ Bendich has also reported vitamin $\mathrm{C}$ as an excellent electron donor to free radicals which subsequently quench their deleterious activity on cellular macromolecules, thus playing a role in antioxidant mechanism. ${ }^{25}$ In our study restoration in the activities antioxidant enzymes might be due to the antioxidant property of ascorbic acid which protect the cell membrane from acetaldehyde induced peroxidative damage thereby it prevents the leakage of cellular content into the circulation. This might be the reason for precipitous drop in the level of liver marker enzymes (bilirubin, AST, ALT, ALP and LDH) in the circulation. This shows that ascorbic acid stabilises the plasma membrane as well as repair the hepatic damage caused by the ethanol. Our results are further supported by our histopathological examination which shows that ethanol causes inflammation and congestion around the central vein. Treatment with ascorbic acid apparently annulled degenerative threats posed by ethanol on the architectural features of hepatocyte in the rats. The architectural organization of the hepatocyte was almost completely restored to normal. The effects noticed were in consonance with the results of our biochemical analysis which shows recovery towards normalization of serum enzymes. This might be attributed to antioxidant effect of ascorbic acid. Cell death in liver mainly occurs by apoptosis or necrosis. Numerous studies focused on molecular mechanism of apoptosis. Activation of Caspase 3 is considered to be the major event during the apoptotic stimuli and it is responsible for cleaving various proteins. Caspase 3 activation may take place through intrinsic mitochondrial pathway or through extrinsic death receptor mediated pathway. On the other hand, Caspase activation also associated with necrosis. $\mathrm{Bcl} 2$ act as an antioxidant and it also block the mitochondrial Caspase 3 activation. Bcl-2 will regulate the mitochondrial intracellular ca+ and product the membrane from pro apoptotic stimuli. ${ }^{2}$ Liver cells, especially hepatocyte is particularly susceptible to death receptor-mediated apoptosis. Overall expression of proapoptotic protein Bax was reported in hepatits. Haorah et al in their study stated that oxidative damage to mitochondria and mitochondrial dysfunction occur with ethanol induced apoptosis which results in up regulation of apoptotic proteins Bax, Caspase 3, Caspase 9 and down regulation of the antiapoptotic $\mathrm{Bcl}-2$ protein. ${ }^{26} \mathrm{In}$ our current study, we observed the significant increase in Bax, Caspase 3, Caspase 9 protein and decrease in Bcl-2 protein in ethanol treated animals indicating the susceptibility of hepatocyte to apoptosis. Apoptosis is a key feature of so many diseases of the liver, therapeutic modulation of liver cell death holds promise. Treatment with ascorbic acid down regulated the expression of Bax, Caspase 3, Caspase 9 and unregulated the expression of Bcl-2. Wenzel et al declared that ascorbic acid functions as a potent antioxidant in mitochondria and control the free radical security pathway and implicated in the suppression of oxidative damage and apoptosis. ${ }^{27}$ On the other hand Alhusaini AM et al in their study reported that ascorbic acid increased the expression of $\mathrm{Bcl}-2$ and diminish the expression of Bax. ${ }^{28}$ Our study revealed that ascorbic acid protect the hepatocytes from the apoptosis by increased the expression of Bcl-2 there by it prevent the mitochondrial Caspase activation. This might be the reason for decreased levels of Caspase 3 and Caspase 9 in our study. In the current study ethanol increased level of LPO and proapoptotic proteins (Bax, Caspase 3 and Caspase 9) and decreased level of antioxidant and antiapoptotic protein (Bcl-2). Ascorbic acid reversed the 
toxic effect of ethanol and protects the hepatocyte from the oxidative damage and apoptosis. Similarly ascorbic acid has the ability to indirectly augment the glutathione level aiding in hepatic detoxification.

\section{CONCLUSION}

Ascorbic acid as an antioxidant controls the free radical security pathway and prevent the mitochondrial Caspase activation and prevent the hepatocyte from the ethanol induced oxidative damage and apoptosis. Ascorbic acid found in citrus fruits, kiwi fruits, berries etc., intake of foods rich in ascorbic acid will protect the liver from alcoholic liver damage.

\section{Funding: No funding sources}

Conflict of interest: None declared

Ethical approval: The study was approved by the Institutional Ethics Committee

\section{REFERENCES}

1. Pal P, Ray S. Alcoholic liver disease: a comprehensive review. EMJ 2016;1(2):85-92.

2. Kapasi AA, Patel G, Goenka A. Ethanol promotes T cell apoptosis through the mitochondrial pathway. Immunology. 2003; 108:313-20.

3. Wu D, Cederbaum AI. Alcohol, oxidative stress and free radical damage. Alcohol Res Health. 2003;27: 277-84.

4. Koch OR, Pani G, Borrello S, Colavitti R, Cravero A, Farre $\mathrm{S}$, et al. Oxidative stress and antioxidant defenses in ethanol-induced cell injury. Mol Asp Med. 2004;25:191-8.

5. Stangeland T, Remberg, SF, Lye KA. Total antioxidant activity in 35 Ugandanfruits and vegetables. Food Chem. 2008;113:85-91.

6. Xavier SM, Barbosa CO, Barros DO, Silva RF, Oliveria AA, Freitas RM. Vitamin C antioxidant in hippocampus of adult Wistar rats after seizures andstatus epilepticus induced by pilocarpine. Neurosci Lett. 2007;420:76-9.

7. Adikwu E, Deo O. Hepatoprotective effect of vitamin C (ascorbic acid). Pharmacol Pharmacy. 2013;4:8492.

8. Tarasankar M, Ayaz A, Pahari N. Evaluation of hepatotherapeutic effects of Mikania Scandens (L.) Willd. On alcohol induced hepatotoxicity in rats. Int J Pharm Pharm Sci. 2012;4(3):490-4.

9. Basini J, Mohanalakshmi S, Anitha k. Protective effect of Mirabilis jalapa leaves on Anti-tubercular drugs induced hepatotoxicity. Asian J Pharm Clin Res. 2013;6:221- 24.

10. Ibrahim MA, Buhari GO, Aliyu AB. Amelioration of Monosodium Glutamate- Induced Hepatotoxicity by Vitamin C. Eur J Sci Res. 2011;60:159-65.

11. Ohkawa H, Ohishi N, Yagi K. Assay of lipid peroxide in animal tissue by TBA reaction. Anal Biochem. 1979;95:351-8.
12. Kakkar P, Das B and Viswanathan PN. A modified spectrophotometric assay of SOD. Indian J Biochem Biophys. 1984; 21:130-2.

13. Sinha AK. Colorimetric assay of catalase. Anal Biochem 1972;47:389-94.

14. Rotruck JT, Pope AL, Ganther HE, Swanson AB, Hafeman DG, Hoekstra WG. Selenium, Biochemical role as a component of glutathione peroxidase. Science. 1973;179:588-90.

15. Omaye ST, Turnbull JD, Sauberlich, HE. Selected methods for the determination of ascorbic acid in animal cells, tissues and fluids. Methods Enzymol. 1979;62:1-11.

16. Desai ID. Vitamin E analysis methods for animal tissues. Methods Enzymol. 1984;105:138-44.

17. Lowry OH, Rosebrough NJ, Farr AL, Randall RJ. Protein measurement with Folin's phenol reagent. J Biol Chem. 1951;193:265-75.

18. Zakhari S, Li TK. Determinants of alcohol use and abuse: Impact of quantity and frequency patterns on liver disease. Hepatology. 2007;46:2032-9.

19. Zima T, Fialova L, Mestek O, Janebova M, Crkovska J, Malbohan I, et al. Oxidative stress, metabolism of ethanol and alcohol-related diseases. J Biomed Sci. 2001;8:59-70.

20. Soo-Jung L, Seon-Young K, Hyesun M. Effects of vitamin $\mathrm{C}$ and $\mathrm{E}$ supplementation on oxidative stress and liver toxicity in rats fed a low-fat ethanol diet. Nutr Res Pract. 2013;7(2):109-14.

21. Das SK, Mukherjee S, Gupta G, Rao DN, Vasudevan DM. Protective effect of resveratrol and Vitamin E against ethanol -induced oxidative damage in mice: Biochemical and immunological basis. Indian $\mathbf{J}$ Biochem Biophysics. 2010;47:32-7.

22. Tuma DJ, Thiele GM, Xu D, Klassen LW, Sorrell MF. Acetaldehyde and malondialdehyde react together to generate distinct protein adducts in the liver during long-term ethanol administration. Hepatology. 1996;23:872-80.

23. Leelavinothan P, Asaithambi K, Paramasivam K, Ayyasamy R. Protective effects of hesperidin on oxidative stress, dyslipidaemia and histological changes in iron-induced hepatic and renal toxicity in rats. Toxicol Rep. 2015;2:46-55.

24. Elias A, Oputiri D. Hepatoprotective effect of vitamin C (Ascorbic Acid). Pharmacol Pharmacy. 2013;4:8492.

25. Bendich A. In: Bendich A, Chandra, RK, eds. Micronutrients and Immune Functions. New York: Academy Sciences; 1990:175.

26. Haorah J, Ramirez SH, Floreani N, Gorantla S, Morsey B, Persidsky Y. Mechanism of alcoholinduced oxidative stress and neuronal injury. Free Radic Biol Med. 2008;45:1542-50.

27. Uwe W, Alexander N, Sabine K, Hannelore D. Ascorbic acid suppresses drug-induced apoptosis in human colon cancer cells by scavenging mitochondrial superoxide anions. Carcinogenesis. 2004;25,703-12. 
28. Alhusaini AM, Faddah LM, Hasan IH. Vitamin C and turmeric attenuate Bax and $\mathrm{Bcl}-2$ proteins' expressions and dna damage in lead acetate-induced liver injury. Dose Response. 2019;17:155.
Cite this article as: Shanmugam N, Siddharaman R, Ekambaram M, Rajendran R, Ramasamy Y,

Balasubramanian A. Ascorbic acid attenuates ethanol induced apoptotic and oxidative response by blocking the Bax, $\mathrm{Bcl} 2$ and Caspase signaling pathways. Int $\mathrm{J}$ Basic Clin Pharmacol 2022;11:137-43. 